\title{
KEKUATAN TATA LETAK FONEM DALAM STRUKTUR LEKSIKON UNIK BASA SEMARANGAN
}

\author{
M. Suryadi dan Sri Puji Astuti \\ Fakultas Ilmu Budaya Universitas Diponegoro Semarang \\ mssuryadi07@gmail.com \& sripujiastuti0116@gmail.com
}

\begin{abstract}
Abstrak
Basa Semarangan memiliki kekayaan dan keunikan terutama dalam penjajaran fonem pada struktur internal leksikon dan kekuatan meaning dalam setiap leksikalnya. Dua hal ini lah yang banyak menduga bahwa Basa Semarangan adalah dialek yang berbeda. Penelitian ini mengkaji kekuatan tata letak fonem dalam struktur leksion unikyang terkait dengan perbedaan meaning, baik yang terkait dengan perluasan dan penyempitan arti. Lokasi penelitian di Kota Semarang, terfokus pada dua area di sepanjang Sungai Banjirkanal, yakni Mrican dan Barito. Ancangan penelitian linguistic structural terfokus pada kajian fonologi. Metode penelitian deskriptif kualitatif. Data dikumpulkan melalui wawancara terstruktur dan mendalam. Data dianalisis menggunakan metode agih dengan piranti teknik pemetaan, liniaritas dan harmonisasi. Hasil penelitian ditemukan bahwa kekuatan tata letak fonem dalam Basa Semarangan memiliki kekuatan dalam membangun arti baru, sehingga leksikon yang muncul menjadi varian-varian leksikon dan leksikon baru. Leksikon baru dapat dikategorikan sebagai leksikon unikyang memiliki sosiokultural dan daya emotif.
\end{abstract}

Kata Kunci: fonem, unik, Basa Semarangan, leksikon.

\begin{abstract}
Semarangan language had riches and uniqueness, especially in the sequence of phonemes in the lexicon internal structure and strength in each lexical meaning. These two things made many people suspect that Semarangan language was different dialect. This research examined the strength of the phonemes layout in the unique lexicon structure that associated with different meanings, both expansion and constriction of meaning. The research location in Semarang city, focused on two areas in along the Banjirkanal river, namely Merican and Barito. The approach of research at structural linguistic was focused on the study of phonology with a descriptive and qualitative methods. Data collection used in-depth interviews and structured interviews. Data analysis used distributional methods with device mapping techniques, mapping and harmonization. The findings of research were the strength of the phoneme layout in Semarangan language that had a strength in building a new meaning. Therefore, the lexicon that appeared, became variants of lexicon and a new lexicon. The new lexicon could be categorized as socio-cultural lexicon that had a unique and emotive power.
\end{abstract}

Keywords: phoneme, unique, Semarangan Language, the lexicon. 


\section{Pendahuluan}

Kehidupan masyarakat Jawa tidak dapat dilepaskan dengan ring alur kehidupan sebagai mahluk sosioal, yang selalu mengindahkan pranata sosial - emosi sosial - kultur sosial. Akibatnya apa yang dilakukan dan dituturkan selalu mempertimbangkan keselarasan, keharmonian, kerukunan, sekaligus mau menekan diri sendiri untuk kepentingan umum. Keharmonisan, kerukunan, dan kegotong-royongan berada pada barisan terdepan dalam kehidupan Jawa, termasuk di dalamnya cara bertutur orang Jawa. Kesantunan dan menghormati orang lain adalah salah satu factor terbentuknya undha-usuk basa Jawa atau tingkat tutur bahasa Jawa.

Basa Semarangan adalah identitas tuturan bahasa Jawa yang diujarkan oleh komunitas masyarakat Semarang yang berada di wilayah pesisir utara Jawa. Penutur Basa Semarangan membangun identitas diri atau jati diri melalui fitur-fitur lingualnya. Fitur lingual tersebut berbeda dengan bahasa Jawa standar. Keperbedaan fitur ini kadangkala Basa Semarangan dianggap sebagai dialek yang berbeda. Keperbedaan fitur tersebut pada tataran etnokomunikasi, kesantunan, varian leksikal, perbaruan meaning, dan tata urutan fonem pada struktur leksikalnya.

Keunikan leksikon pada Basa Semarangan tersimpan dalam varian-varian leksikon yang wilayah persebarannya berada pada ring Sungai Banjir Kanal. Pada penelitian ini dibatasi pada area selatan: Mrican dan area utara: Barito. Pemilihan dua wilayah ini dilakukan untuk mempertajam area persebaran Basa Semerangan.

\section{Tinjauan Pustaka}

Tinjauan pustaka pada penelitian ini lebih difokuskan pada (1) hakiki budaya Jawa, (2) bentuk bertutur santun, (3) bahasa Jawa Pesisiran, dan (4) struktur internal bahasa Jawa.

\subsection{Hakiki Budaya Jawa}

Kajian hakiki budaya Jawa menjadi sumber rujukan utama, hal ini bertautan dengan pranata dan aturan social yang harus dipatuhi oleh masyarakat penganutnya. Kajian hakiki budaya yang dijadikan sebagai sumber rujukan, sebagai berikut.

a. $\quad$ Mulder (1985): Pribadi dan Masyarakat di Jawa

Karya Mulder (1985) ini berisi tentang pandangan kejawen, kepribadian masyarakat Jawa, ekspresi kehidupan sehari-hari, dan hubungan antara pribadi dan masyarakat, yang dalam kehidupan bermasyarakat dibatasi oleh tatanan atau norma tertentu dan (harus) dipatuhi, untuk bisa hidup selaras. Keselarasan yang dimaksudkan disini adalah kepatuhan masyarakat untuk mematuhi aturan yang ditetapkan secara konvensional. Pribadi Jawa di dalamnya termasuk komponen alam dan keseimbangan. Karya ini digunakan sebagai parameter penggunaan leksikon emotif dialektis terhadap setting tuturan yang diwarnai dengan warna budaya Jawa.

b. Suseno (1985) : Etika Jawa: Sebuah Analisa Falsafi tentang Kebijaksanaan Hidup Jawa Karya Suseno (1985) ini sangat penting dan menjadi rujukan, karya ini memuat kaidah dasar kehidupan masyarakat Jawa, yang di dalamnya mengandung unsur prinsip kerukunan, prinsip hormat, etika keselarasan sosial, dan juga menjelaskan pandangan dunia Jawa, serta etika sebagai kebijaksanaan hidup. Rujukan ini akan dipilahkan terutama yang terkait dengan keselarasan kerjasama yang diwujudkan melalui referensi leksikon sebagai hasil budidaya masyarakat pesisir, terutama keunikan pembentukan leksikal emotif dialektis oleh penutur Jawa di Semarangan. 


\subsection{Bentuk Bertutur Jawa}

Kajian bentuk bertutur bahasa Jawa, tidak dapat dilepaskan dengan kaidah kerja-sama dan kesantunan. Adapun teori yang terkait dengan aturan kerja-sama dan kesantunan adalah: a. Brown and Levinson (2000): Politeneess in some Universal in Language Usage Karya Brown and Levinson (1992) memberikan parameter bahwa untuk berbicara santun pada hakikatnya adalah berbicara untuk menjaga perasaan peserta tutur lainnya. Untuk dapat menjaga perasaan tersebut setiap penutur harus mengikuti ketentuan sebagai berikut.

1) Memperhatikan harga diri mitra tutur dengan memperlakukan sebagai orang yang memiliki kedudukan yang sama atau strategi positif (positive strategy)

2) Memperlakukan sedemikian rupa sehingga tidak mengurangi kebebasan dalam bertindak tutur atau strategi negative (negative strategy)

b. Sukarno 2010, "The Reflection of the Javanese Cultural Concepts in the Politeness of Javanese"

Sukarno (2010) memberikan ketagasan bahwa nilai kesantunan dalam bahasa Jawa banyak dipengaruhi oleh budaya dasar di mana penutur tinggal (pusat budayapesisiran). Dasar apapun kesantunan Jawa tidak dapat dilepaskan oleh unsur: tata krama, andhap-asor, dan tanggap ing sasmita. Konsep ini telah diuji dengan teori Brown dan Levinson (2000), Leech (1983), Grice (1981), dan Lakoff (1990). Karya ini hanya terfokus pada pola kesantunan bahasa Jawa yang digunakan di wilayah sentra budaya (Solo-Jogja), namun kesantunan yang jauh dari pusat budaya (wilayah pesisiran) belum dikaji.

\subsection{Bahasa Jawa Pesisiran}

Kajian yang terfokus wilayah pesisir terutama yang terkait dengan ciri dialektis yang berada di lingkungan pesisir, terutama pesisir utara Jawa Tengah. Adapun karya ilmiah yang dimanfaatkan dalam penelitian ini adalah.

a. Hartono (2010): "Bahasa Semarangan, Bahasa Tutur Miskin Literatur"

Hartono (2010) mengkaji bahasa Semarangan, karya ini dapat dikategorikan sebagai kajian lokabasa. Artikel ini dirujuk dengan dasar pertimbangan adanya kesamaan terhadap lokasi penelitian, yakni Kota Semarang. Diharapkan melalui karya ilmiah ini dapat ditemukan karakter tuturan Semarangan. Namun, Hartono (2010) hanya memuat beberapa kata yang dianggapnya sebagai bahasa Semarangan. Disayangkan karya ini tanpa kajian teori linguistik, hanya kumpulan kosakata yang diyakini sebagai kosakata asli bahasa Jawa Semarangan.

b. Vander Klok, J (2015): "The Dichotomy of Auxiliaries in Javanese: Evidence from Two Dialects"

Vander Klok (2015) melakukan penelitian dialek geografi di wilayah Paciran dengan membandingan pada bahasa Jawa standar (Yogyakarta dan Solo). Secara sekilas disinggung pula perihal penggunaan bahasa Jawa di Kota Semarang khususnya pada peranakan Jawa. Metode penelitian yang digunakan Vander Klok (2015) adalah elisitasi dan rating likert melalui intrumen penelitian: kuesioner. Hasil penelitian ditemukan bentuk kalimat dalam tuturan cenderung berbentuk topikalisasi ( $\mathrm{V}-\mathrm{O}$ ) dengan pelesapan subjek. Temuan ini dimanfaatkan sebagai bahan pertimbangan teori: korelasi antara bentuk (gramatikal) dengan sosiokultural (topikalisasi ujaran). 


\subsection{Struktur Internal Bahasa Jawa}

Kajian struktur internal bahasa Jawa dimanfaatkan untuk mempertajam analisis yang terkait dengan struktur internal lingual, baik yang mencakup linguistik murni atau linguistik mikro yang memfokuskan pada kajian struktur leksikal, sintaksis, dan semantik. Adapun kajian struktur internal bahasa Jawa yang dijadikan bahan rujukan sebagai berikut.

a. Wedhawati, dkk (2010): Tata Bahasa Jawa Mutakhir

Wedhawati dkk (2010) mengkaji secara deskriptif struktur bahasa Jawa. Kajian dimulai dari tataran kata baik dari segi morfemis maupun kategori kata, dilanjutkan pada tataran frasa dan tataran kalimat. Karya ini lebih didominasi pada kaidah pembentukan kata secara morfemis, sehingga banyak ditemukan pola penggabungan antarmorfem. Sumber data yang digunakan adalah bahasa Jawa standar (SoloYogyakarta). Keutamaan karya ini adalah memilah-milah bentuk kata berdasarkan kaidah morfemis, sehingga dihasilkan kaidah tata bahasa baku bahasa Jawa. Tuturan lingual natural (parole) dalam peristiwa tutur sehari-hari tidak tersentuh. Tuturan porole inilah yang menjadi sumber primer dalam kajian linguistik.

b. Keeler, W. (2015): "Javanese Grammar for Students: A Graded Introduction"

Keeler (2015) mengungkapkan bahwa salah satu strategi belajar tata bahasa Jawa bagi para pelajar dapat dilakukan melalui pemahaman sosio-kultural budaya Jawa. Diberikan contoh kasus pengucapan (pronunciation) kosakata dapat dilafalkan tepat manakala paham budaya Jawa. Dengan demikian, belajar bahasa Jawa tidak cukup hanya memahami kalimat per kalimat namun juga harus memahami penempatan kalimat tersebut dalam ujaran sehari-hari. Belajar tata bahasa Jawa lebih komprehensif tidak cukup hanya belajar kaidah namun sebaiknya tinggal di tanah Jawa. Karya ini dimanfaatkan sebagai kekuatan teori bahwa bahasa (grammar) terkait erat dengan budaya (cultur).

\section{Metode Penelitian}

\subsection{Lokasi Penelitian}

Lokasi penelitian ini berada di wilayah pesisir utara Jawa Tengah, yang difokuskan di Kota Semarang, terutama pada ring pemakaian Basa Semarangan. Terutama pada ring aliran Sungai Banjir Kanal bagian selatan: Mrican dan aliran bagian utara: Barito. Pemilihan wilayah kedua titik pengamatan tersebut, didasarkan atas pertimbangan sebagai berikut.

a. Pertimbangan umum: Titik pengamatan di Mrican dan Barito adalah wilayah persebaran ekonomi, kedua titik pengamatan ini memiliki area transaksi jual-beli, yakni Pasar Mrican dan Pasar Barito. Diharapkan di dua wilayah ini banyak ditemukan bentuk tuturan yang terkait dengan Basa Semarangan.

b. Pertimbangan khusus: Titik pengamatan Mrican sebagai sentra perdagangan tradisional (pasar tradisional: kebutuhan pokok sehari-hari), diharapkan tuturan Basa Semarangan juga lekat dalam transaksi jual beli, terutama dalam gender perempuan. Titik pengematan Barito sebagai sentra perdagangan alat-alat kendaraan/mesin, diharapkan tuturan Basa Semarangan juga dapat dideteksi pada tuturan gender lakilaki.

\subsection{Pengumpulan Data}

Data dalam penelitian ini meliputi data primer dan data sekunder. Data sekunder digunakan untuk mendukung data primer, pengumpulannya dilakukan dengan metode 
simak yang dikembangkan dengan Teknik Dasar Sadap dan teknik lanjutan berupa Teknik Catat dan Teknik Rekam (Sudaryanto, 1988). Data sekunder diperoleh dari: (1) BPS Kota Semarang dan Propinsi Jawa Tengah yang berwujud profil wilayah penelitian; (2) Litbang dan Humas Pemkot untuk memperoleh karakteritis masyarakat pesisiran secara menyeluruh dan menggali faktor-faktor dominan yang mewarnai masyarakat tersebut, dapat berupa sosiokultural dan meliu. Hal ini sangat penting sebagai informasi awal dalam penentuan sampel dan mengetahui secara agregat perwatakan masyarakat pesisiran.

Pengumpulan data primer dilakukan dengan cara trianggulasi dengan beberapa metode, yakni: obsevasi, wawancara terstruktur (structured interview), wawancara mendalam (indepth interview), dan diskusi kelompok terfokus (focus grop discussion).

\subsection{Analisis Data}

Dalam penelitian ini, data dianalisis menggunakant metode agih dengan empat piranti analisis, yakni:

a. Teknik pemetaan, teknik ini digunakan untuk mengurai urutan fonem dalam struktur interna leksikon yang ditengarai sebagai unique lexical.

b. Teknik penjajaran digunakan untuk merunut tata letak urutan fonem yang terkait dengan kekuatan makna yang dimiliki unique lexical.

c. Teknik harmonisasi fona digunakan sebagai kepaduan bunyi terhadap bentukan leksikon dari hasil migrasi fonem.

\section{Hasil dan Pembahasan}

Bahasa Jawa yang digunakan oleh penutur Jawa di Kota Semarang memiliki fitur yang berbeda dengan bahasa Jawa standar. Perbedaan yang muncul dapat ditengarai sebagai ciri sebagian dari bahasa Jawa yang berada di wilayah pesisir utara Jawa Tengah. Selain berbeda dengan bahasa Jawa standar, kedua tuturan Jawa tersebut juga memiliki ciri-ciri kedaerahan, yang berbeda satu dengan yang lainnya. Fitur basa Semarangan melekat pada bunyi ujaran, kosakata dialectal dan pembentukan kosakat.

\subsection{Bunyi Ujaran}

Bunyi ujaran adalah kecap ujaran yang menyertai tuturan secara sertamerta dan melekat secara emosional dalam diri penutur. Ikatan emosional ini tertanam sejak penutur mengenal bahasa ibunya. Bunyi ujaran dapat digunakan sebagai alat bantu untuk mengenali asal-usul daerah penutur.

Fungsi kecap ujaran dalam tuturan adalah penegas maksud atau tujuan dari apa yang diucapkan, kadangkala hanya berfungsi sebagai penyelaras ujaran agar tampak logat kedaerahannya (bersifat dialektis). Kecap ujaran pada umumnya berada dalam kategori fatis dan sering melekat pada tuturan beragam ngoko lugu. Beberapa bentuk kecap ujaran yang kerap kali dipakai oleh penutur Jawa di Kota Semarang, antara lain tertera pada data di bawah ini.
(1) $\quad \ldots i k$
(2) ...ok
(3) he eh
(4) piye jal
(5) Iha
(6) lha ik
(7) lha ya 
(8) sip

(9) to yo

(10) ndhak yo

Kecap ujaran di atas sebagai identitas tuturan penutur Jawa di Kota Semarang. Posisi kecap ujaran dalam tuturan dapat terletak pada awal maupun akhir tuturan. Letak dalam tuturan banyak dipengaruhi oleh topikalisasi tuturan dan emosi sesaat pada saat tuturan beralangsung. Letak kecap ujaran dalam tuturan tercermin dalam tuturan di bawah ini.

(1) Lha ya rak mang ita itu 'tidak usah bertingkah'

(2) Asem, malah lungo ik 'pisuhan, langsung pergi'

(3) Gayane kemlinti ok 'gaya luar biasa'

(4) He eh lheb ghodek 'benar-benar hebat'

(5) Piye jal mlengse 'bagaimana ini'

\subsection{Leksikon Dialektal}

Leksikon dialektal sebagai salah satu fitur yang dimiliki oleh semua tuturan yang terkait dengan lokasi geografi. Fenomena ini terjadi juga dalam tuturan Jawa yang dipakai oleh penutur Jawa di Kota Semarang. Leksikon dialektal sebagai ruh bahasa ibu penutur. Hal ini, mengisyaratkan bahwa leksikon dialektal sebagai penyalur emosi yang kuat, identitas kedaerahan karena wilayah sebaran cukup terbatas, dan ringan dalam tuturan. Beberapa leksikon dialektal yang berkembang di wilayah tuturan Kota Semarang tertera pada data di bawah ini.
(1) bak-buk
'impas'
(2) balangan
'barang bekas'
(3) blaik
'ungkapan kaget'
(4) ciamik
'hebat'
(5) denok \& kenang
'mbak dan mas'
(6) gilo-gilo
'penjual aneka jajanan pasar didorong gerobak di pasarkan malam hari
(7) gombal mukiyo
'rayuan'
(8) ita-itu
'bertingkah'
(9) kas
'sapaan akrab untuk laki-laki'
(10) kenthip
'sangat jauh'

\subsection{Leksikon Unik}

Leksikon unik adalah leksikon yang area persebarannya pada wilayah tertentu dan hanya dipahami oleh komunitas tertentu, termasuk di dalamnya adalah penutur basa Semarangan di wilayah titik pengamatan Mricen dan Barito. Pembentukan kosakata unik adalah penjajaran fonem yang dianalogikan melalui metode padan dengan membandingkan pada ururan aksara Jawa di luar tuturan lingualnya. Adapun kosakata yang hasil bentukannya, sebagai berikut.
(1) calam : bapak
(2) denyom : wanita
(3) gomom : rokok
(4) : :ibu 


$\begin{array}{ll}\text { (5) ngamu } & \text { : aku } \\ \text { (6) mode } & \text { : kamu } \\ \text { (7) patang } & \text { : laki-laki } \\ \text { (8) Kas mode ngipang } & \text { : mas kamu (kok) hilang } \\ \text { (9) Kahat Gus } & \text { : makan siang mas } \\ \text { (10) Ngoto ngolo } & \text { :ada apa }\end{array}$

\subsection{Analisis Unique Lexical}

Leksikon unik (unique lexical) yang menjadi khas basa Semarangan sebagian dapat dirunut proses pembentukannya. Hartono memberikan rumusan pembentukan leksikon unik berdasarkan menukar urutan aksara Jawa. Rumusan yang ditawarkan konsep Hartono (2010:28) sebagai berikut.

"Urutan yang benar huruf Jawa adalah:

Ha, Na,Ca, Ra, Ka, Da, Ta, Sa, Wa, La, Pa, Da, Ja, Ya,Nya, Mang, Ga, Ba, Tha, Nga.

Perumus bahasa prokem semarangan (siapa orangnya saya tidak tahu) membagi 20 huruf Jawa menjadi dua bagian. Sepeluh huruf pertama dibaca sesuai urutannya, sedangkan sepuluh huruf berikutnya dibaca dengan urutan terbalik (lihat tabel)

\begin{tabular}{|c|c|c|c|c|c|c|c|c|c|}
\hline $\mathrm{Ha}$ & $\mathrm{Na}$ & $\mathrm{Ca}$ & $\mathrm{Ra}$ & $\mathrm{Ka}$ & $\mathrm{Da}$ & $\mathrm{Ta}$ & $\mathrm{Sa}$ & $\mathrm{Wa}$ & $\mathrm{La}$ \\
\hline $\mathrm{Nga}$ & Tha & $\mathrm{Ba}$ & $\overline{\mathrm{Ga}}$ & $\mathrm{Ma}$ & Nya & $\mathrm{Ya}$ & $\mathrm{Ja}$ & Dha & $\overline{\mathrm{Pa}}$ \\
\hline
\end{tabular}

Setelah terbentuk kata kemudian ditutup dengan konsonan, biasanya 'm', yang membuat kata baru itu enak diucapkan"

Berdasarkan konsep yang ditawarkan Hartono (2010:28) di atas, bahwa sebagian leksikon unik dibentuk atau dibuat penutur komunitas basa Semarangan dengan memanfaatkan urutan aksara Jawa.

Proses pembentukan leksikon unik (unique lexical) dapat pula dilakukan dengan pemanfaatan urutan fonem. Proses ini dapat dikatakan menyempurnakan proses pembentukan leksikon unik yang ditawarkan oleh Hartono (2010:28). Konsep yang ditawarkan pada penelitian ini adalah memanfaatkan urutan fonem pada aksara Jawa dengan bentuk cakram. Model cakram tersebut dapat diabstraksi pada bagan di bawah ini.

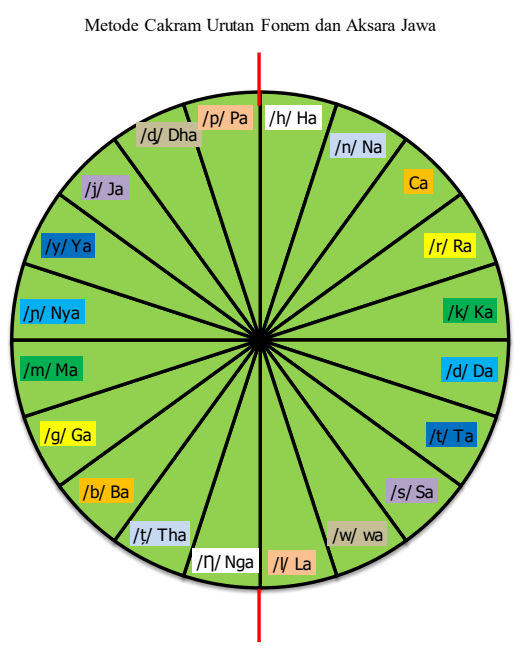


Model cakram urutan fonem aksara Jawa di atas lebih sederhana dan mudah dipahami dan langsung teridentifikasi bentukan leksikon unik (cf: Hartono , 2010:28). Model cakram di atas selain sederhana sebagai model formula, sisi kelebihan lain adalah terdapat penjelasan ilmiah secara linguistic, yakni kaidah urutan fonem dan migrasi fonem.

Model cakram urutan fonem tersebut diawali dengan pemarkah fonem $/ h /$ dan disertai aksara Jawa ha. Setiap fonem pemarka dan aksara Jawa ditandai dengan latar warna yang berbeda. Adapun proses migrasi fonem tersebut dapat diikuti langkah-langkah kerja sebagai berikut.

a. Leksikon sasaran dipilah berdasarkan silabenya, selanjutkan silabe tersebut dipetakan pada model cakram fonem.

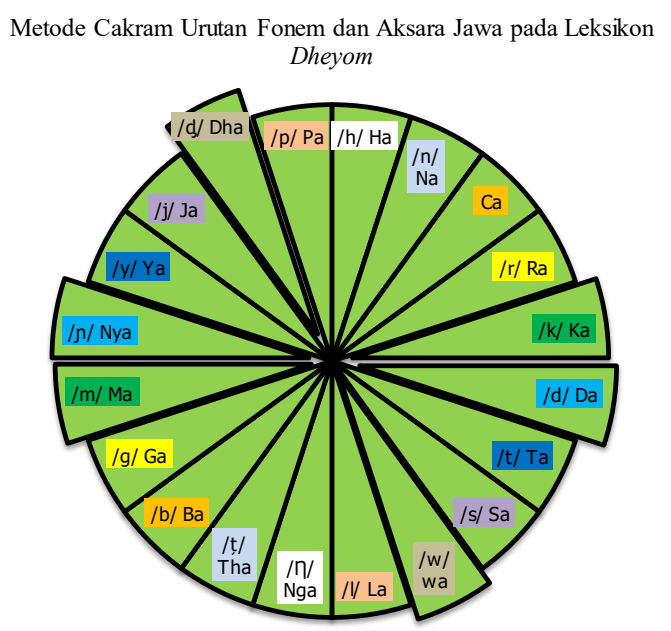

Leksikon sasaran: wedhok memiliki silabe we-dho-k

b. Pemenggalan silabe pada cakram sisi kanan adalah leksikon sasaran dan hasil pemetaan silabe pada cakram sisi kiri adalah leksikon target, yakni dha-nya-ma à dhayama

c. Penyelarasan bunyi: leksikon target atau leksikon bentukan yang dihasilkan melalui model cakram mengalami penyelarasan bunyi atau harmonisasi fona. Dhayama à dheyom.

Temuan metodepenelusuranmodel cakramurutan fonem memilikikelebihan-kelebihan, yakni ada tiga kelebihan yang dapat digunakan sebagai temuan dalam pengembangan ilmu linguistic. Tiga kelebihan tersebut adalah sebagai berikut.

a. Melalui motode cakram dapat ditelusuri proses pembentukan leksikon unik dari leksikon asal.

b. Dapat menemukan leksikon asal atau leksikon sumber dari leksikon unik.

c. Melalui metode cakram dapat secara produktif membangun atau membuat leksikonleksikon unik yang baru.

d. Komunitas basa Semarangan dapat dengan mudah membangun leksikon-leksikon unik baru yang lebih lingual.

\subsection{Metode Pembentukan Unique Lexical}

Pembetukan unique lexical atau leksikon unik dapat dilakukan melalui metode cakram urutan fonem dan aksara Jawa. Leksikon unik dapat dibuat atau dibangun melalui leksikon- 
leksikon yang sudah ada dalam bahasa Jawa. Dengan demikian, pembentukan leksion unik sangat terbuka dan (mungkin) lebih produktif, tergantung kemauan dan keinginan penuturnya. Sifat terbuka ini lah memungkinkan jumlah leksikon unik terus berkembang sebagai sumber kekayaan lingual bagi penutur basa Semarangan.

Proses pembentukan leksikon unik melalui metode cakram urutan fonem dan aksara Jawa sangat sederhana dan mudah. Proses kelanjutannya adalah (bila diperlukan) harmonisasi bunyi atau fonem untuk menyeralaskan leksikon bentukan baru. Beberapa deskripsi proses pembentukan unique lexical dideskripsikan di bawah ini.

a. Leksikon Bapak

Leksikon yang memiliki arti leksikal 'bapak' dalam bahasa Jawa di Kota Semarang memiliki beberapa varian, yakni bapak, bapake, pak, pake dan calam. Kelima varian bentuk leksikon 'bapak' memiliki kadar keemotifan yang berbeda-beda. Gradasi keemotifan kelima varian leksikon tersebut, sebagai berikut.

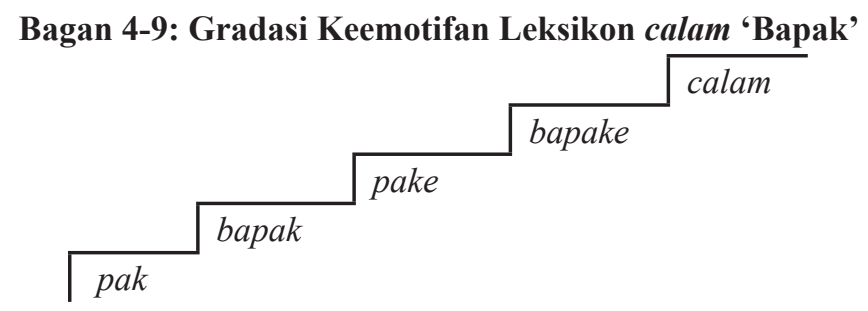

Varian leksikal 'bapak' di atas yang memiliki kekuatan emotif tertinggi terdapat pada leksikon unik calam. Leksikou unik calam 'bapak' dibentuk melalui proses sebagai berikut.

1) Leksikon sasaran bapak 'bapak' dipilah berdasarkan silabenya, selanjutkan silabe tersebut dipetakan pada metode cakram urutan fonem dan aksara Jawa. Bapak à $b a-p a-k$

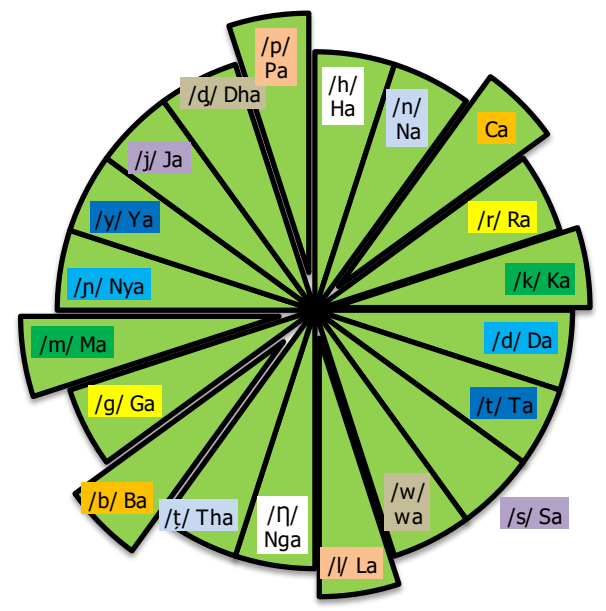

Bagan 4-10: Metode Cakram Urutan Fonem \& Aksara Jawa pada Leksikon Calam 'Bapak'

2) Pemenggalan silabe dimasukan dalam cakram (ditandai dengan bagian cakram yang ditarik keluar). Melalui cakram tersebut silabe yang diterakan pada cakram memiliki silabe hasil pemetaan, yakni silabe

ba à ca

pa à la

$k \grave{a} m$ 
Silabe hasil pemetaan pada metode cakram adalah $\mathrm{ca}$-la- $m$ selanjutnya terbentuk leksikon unik baru calam 'bapak'.

3) Penyelarasan bunyi: leksikon target atau leksikon bentukan yang dihasilkan melalui model cakram tidak mengalami penyelarasan bunyi. Hasil bentukannya tetap calam 'bapak'.

b. Leksikon $I b u$

Kosakata yang memiliki arti leksikal 'ibu' dalam bahasa Jawa di Kota Semarang memiliki banyak varian, yakni ibu, ibuke, mak, make, mbok, mbokke dan ngicu. Ketujuh varian bentuk leksikon ' $i b u$ ' memiliki kadar keemotifan yang berbeda-beda. Gradasi keemotifan ketujuh varian leksikon berarti 'ibu', sebagai berikut.

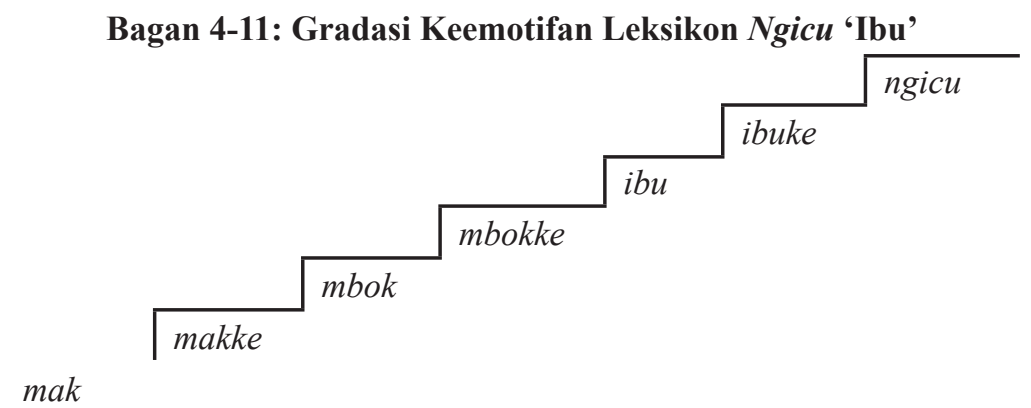

Varian leksikal 'ibu' di atas yang memiliki kekuatan emotif tertinggi terdapat pada leksikon unik ngicu. Leksikou unik ngicu 'ibu' dibentuk melalui proses sebagai berikut.

1) Leksikon sasaran ibu 'ibu' dipilah berdasarkan silabenya, selanjutkan silabe tersebut dipetakan pada metode cakram urutan fonem dan aksara Jawa.

$i b u$ à $i-b u$

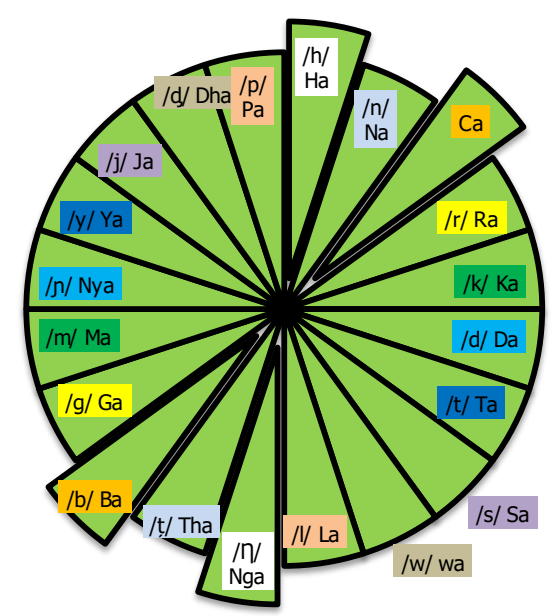

Metode Cakram Urutan Fonem dan Aksara Jawa pada Leksikon Ngicu 'Ibu'

2) Pemenggalan silabe dimasukan dalam cakram (ditandai dengan bagian cakram yang ditarik keluar). Melalui cakram tersebut silabe yang diterakan pada cakram memiliki silabe hasil pemetaan, yakni silabe

$i>h a>h i$ à $n g i$

bu $>b a>b u \grave{a} c u$

Silabe hasil pemetaan pada metode cakram adalah nga-ca selanjutnya terbentuk leksikon unik baru ngicu 'ibu' . 
3) Penyelarasan bunyi: leksikon target atau leksikon bentukan yang dihasilkan melalui model cakram mengalami penyelarasan bunyi, yakni ngaca $>$ ngicu. Hasil bentukannya tetap ngicu 'ibu'.

\section{SIMPULAN}

Hasil penelitian ditemukan bahwa kekuatan tata urutan fonem yang digunakan untuk membangun leksikon unik adalah memanfaatkan analogi lingual lain dalam memadankan varian leksikon baru. Proses pemadanan ini memanfaatkan kekuatan penjajaran fonem pada struktur interna leksikon, liniaritas, pemetaan, dan harmonisasi fona.

Metode cakram sebagai model pembentukan dan penelusuran leksikon unik basa Semarangan, memiliki keunggulan lingual, sebagai berikut.

a. $\quad$ Dapat menelusuri proses pembentukan unique lexical.

b. Dapat menemukan leksikon asal atau leksikon sumber.

c. Dapat secara produktif membuat unique lexical baru.

d. Komunitas basa Semarangan dapat dengan mudah membangun unique lexical baru yang lebih lingual.

\section{Daftar Pustaka}

Brown \& Levinson (2000) Politenees in some Universal in Language Usage.Cambridge: Cambridge U.P.

Hartono. (2010). "Bahasa Semarangan, Bahasa Tutur Miskin Literatur" dalam Seminar Nasional Pemertahanan Bahasa Nusantara. Semarang, 6 Mei 2010: Program Magister Linguistik Undip.

Keeler, W. (2015), 'Javanese Grammar for Students: A Graded Introduction', Asian Studies Review, 39, 4, pp. 692-693, Humanities International Complete, EBSCOhost.

Mulder, N. (1985). Pribadi dan Masyarakat di Jawa. Jakarta: Sinar Harapan.

Purwoko, H. (2008). Jawa Ngoko: Ekspresi Komunikasi Arus Bawah. Semarang: Penerbit Indek.

Sudaryanto. (1988). Metode Linguistik: Bagian Kedua Metode dan Aneka Teknik Pengumpulan Data. Yogyakarta: Gadjah Mada University Press.

. (1991). Tata Bahasa Baku Bahasa Jawa. Yogyakarta: Duta Wacana University Press.

Suseno, F.M. (1985). Etika Jawa: Sebuah Analisa Falsafi tentang Kebijaksanaan Hidup Jawa. Jakarta: Gramedia.

Vander Klok, J. (2015), 'The Dichotomy of Auxiliaries in Javanese: Evidence from Two Dialects', Australian Journal Of Linguistics, 35, 2, pp. 142-167, Humanities International Complete, EBSCOhost.

Wedhawati, et al. (2010). Tata Bahasa Jawa Mutakhir. Yogyakarta: Kanisuus. 